
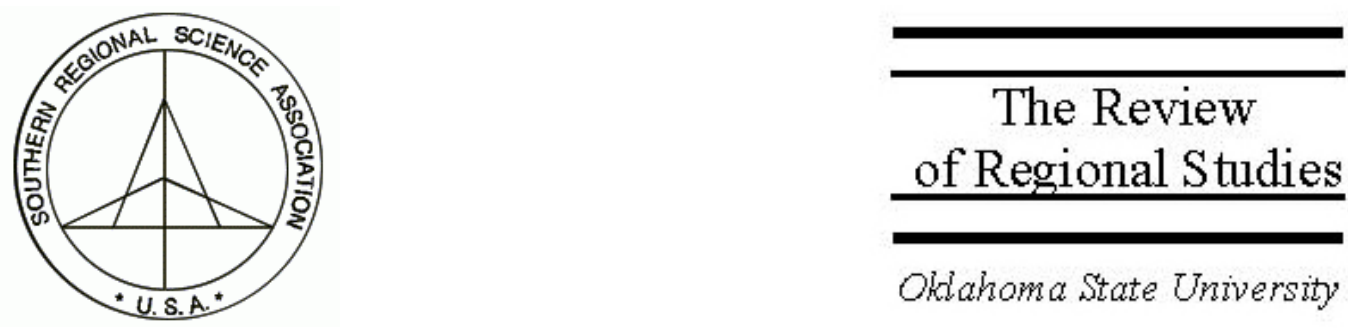

\title{
Do Geographic Entry Restrictions Increase Car Prices?
}

\author{
Michael L. Walden \\ Department of Agricultural and Resource Economics, North Carolina State University, \\ Box 8109, Raleigh, NC 27695-8109, e-mail: michael_walden@ncsu.edu
}

\begin{abstract}
Many states allow existing retail vehicle dealerships to challenge the entry of new competitors. Earlier studies found these restrictions resulted in higher vehicle retail prices. However, the studies used average vehicle prices or proxies for average prices and were not able to control for the numerous features and amenities that differentiate vehicles. The previous work was also conducted prior to the development of Internet shopping. This study tests the impact of state entry restrictions using a new data set that addresses these issues. Regression analysis finds that states having entry restrictions on new dealerships do not have higher vehicle prices.
\end{abstract}

Keywords: Vehicle market, Government regulation

JEL classification: L43; L92; R48

Able research assistance was provided by Dominic Pazzula, Ali Termos, and Julianne Treme. The comments of two reviewers significantly improved the paper while leaving any errors to the author. 


\section{INTRODUCTION}

Purchasing a vehicle is one of the largest financial decisions a household makes, second only to a home purchase. Consumer Expenditure Survey data show the average household spends 9.1 percent of annual income on a vehicle purchase, compared to 12.6 percent for the expenses of home ownership (U.S. Bureau of Labor Statistics 2003). Consumers also purchase vehicles more frequently than homes, so although the monetary outlay for vehicles may be less than for homes, the vehicle purchase decision occurs more often.

In markets, government actions can both help and harm consumers. Government actions can help consumers by promoting competition among sellers, encouraging or requiring the release of product information to consumers, and assisting consumers in the evaluation of this information. But government actions can harm consumers by establishing laws restricting seller competition and by suppressing information and analysis valuable to consumers.

This paper addresses the potential harm government can do to consumers through restriction of competition in the retail vehicle market. Previous studies have examined the adverse effects of governmental entry restrictions in the hospital, trucking, dental care, and taxicab markets (Federal Trade Commission 2004; Daniel and Kleit 1995; Liang and Ogur 1987; Federal Trade Commission 1987). Each of these analyses found that regulations on entry of new competitors limited supply and increased the price paid by consumers.

The new research adds to the work of three earlier studies of geographic entry restrictions in the retail vehicle market completed in the early and mid-1980s (Smith 1982; Eckard 1985; Rogers 1986). The justification for a new study is threefold. First, the number of states with competitive restrictions in the retail vehicle market has increased since the 1980s. Second, the advent of computer technology and Web-based vehicle shopping sites during the past 20 years has likely affected the impact of state competitive restrictions in the retail vehicle market. Third, the paper uses on-line price quotes as part of a much improved data set that better controls for the myriad of vehicle characteristics affecting the vehicle price. Thus, compared to previous studies, we are more assured of comparing the prices of the exact same vehicles.

The plan of the paper is as follows. The next section identifies the way states can restrict competition in the retail vehicle market and reviews previous studies of these restrictions. The third section establishes the model used for analyzing state restrictions in the retail vehicle market and presents the data used for estimating the model. Empirical results and analysis are presented in the fourth section, and implications and conclusions are given in the final section. 


\section{STATE GEOGRAPHIC RESTRICTIONS IN THE RETAIL VEHICLE MARKET: DESCRIPTION AND PAST ANALYSIS}

In market competition unconstrained by government regulations, a potential new firm decides whether to enter a market based on an evaluation of benefits and costs. Of course, the firm may be required to purchase government licenses. But certainly the firm would not be required to justify to private or public bodies the rationale for establishing operations in the market.

Yet this is exactly what is required by a majority of states (45) for potential retail vehicle dealers, including all but one southern state. ${ }^{1}$ Suppose some investors want to open a new vehicle dealership in State A. Once the dealership is proposed, existing dealerships selling the same company brand (e.g., existing Ford dealerships if the proposed dealership is Ford, or existing Lexus dealerships if the proposed dealership is Lexus) in the "retail market area" can file a protest. The retail market area (RMA) is defined by each state by a radius mileage from the location of the proposed dealership. ${ }^{2}$ A formal proceeding before a specially constituted board is held to determine whether the proposed dealership is "justified." The composition of the board varies between states and can include state officials, representatives of the dealership industry, and consumer representatives. Although there has been no comprehensive national cataloguing of the outcomes of these proceedings, a Florida study found 29 percent of the proposed new auto dealerships in the state between 1989 and 1995 were denied by this process (Florida Office of Program Policy Analysis 1996).

This procedure can deter entry of new vehicle dealerships in three ways. First, some proposed dealerships can be denied. Second, the possibility of being denied may deter some investors from proposing a new dealership. Third, the existence of the procedure imposes costs for the investors, and this will make any benefit/cost analysis for a new dealership less attractive than in the situation with no procedure. For consumers, the important issue is whether these entry restrictions protect existing dealerships from new competition. If so, the restrictions could mean higher prices for vehicles and reductions in buyer welfare.

Three previous studies have estimated the market impacts of state geographic entry restrictions on retail vehicle dealerships. Smith (1982) found evidence that the state entry restrictions reduced the number of dealerships and increased vehicle prices in the two years 1954 and 1972. However, the year for which Smith had information on state entry restrictions, 1979, did not correspond to either of his study years. Also, Smith used an average for each state for the price variable, defined by total dealer revenue per new car

\footnotetext{
${ }^{1}$ The south region is defined to include Alabama, Arkansas, Florida, Georgia, Kentucky, Louisiana, Mississippi, North Carolina, Oklahoma, South Carolina, Tennessee, Texas, Virginia, and West Virginia. Mississippi is the only state without geographic entry restrictions in the retail vehicle market.

${ }^{2}$ The retail market areas for each state are available upon request from the author.
} 
registration, rather than the market prices of actual vehicles. Thus, there is no assurance the prices of the same vehicles with the same characteristics were compared.

Eckard (1985) used proprietary data from General Motors for 5,717 Chevrolet dealers in operation in 1978. After controlling for dealer costs and demographic variables in the market, he found auto prices were approximately 1 percent higher in states with entry restrictions. Although Eckard improved on Smith's (1982) analysis by estimating separate equations for each of seven Chevrolet product types (Malibu, Nova, Monte Carlo, Monza, Chevette, Camero, Regular), again there was no assurance the specific characteristics in each car type were the same. That is, for example, even though only Malibu prices in Ohio were compared to Malibu prices in Georgia, it is likely a higher percentage of Malibus in Georgia were sold with air-conditioning than in Ohio. Therefore, the same Malibus were not being compared in Ohio and Georgia. Also, Eckard's price variable was revenue from sales of a car type divided by the number of sales of that type, not the observed sales price.

The third and most comprehensive study was done by Rogers (1986) for the Federal Trade Commission. He used Eckard's (1985) data plus two additional car models to estimate supply and demand curves for each of the models. His major finding was that state entry restrictions only affected car prices when interacted with population growth. The greater the population growth in an area, the greater should be the demand for additional dealerships, and the more limiting will be the entry restrictions. Rogers estimated the laws restricting dealer entry increased car prices 6 percent and cost actual and potential car purchasers $\$ 3.2$ billion annually in 1985 prices.

Since Rogers (1986) used the same data as Eckard (1985), Rogers' study suffers from the same problem of not controlling for differences in car options, even among the same car model. To his credit, Rogers recognized this problem. He did attempt one solution by including the average July temperature in the location where the car was purchased as a proxy for the air-conditioning option, but the results for this variable were mixed. In fact, the results for most of Rogers' control variables were poor, which he attributes to data inadequacies.

So the findings from the three previous studies are unsatisfactory on several counts. First, the measures of vehicle price did not adequately control for differences in features and options even in the same vehicle model. Second, information technology has likely dramatically changed auto purchasing behavior since 1978, the year for the most recent data used in the studies. The availability of Internet shopping would seem to reduce the effects of entry restrictions by easily allowing buyers to shop over a wider geographic area. Third, since many of the entry restrictions in some states have been in effect for over two decades longer since the earlier studies, welfare losses may be larger. For these reasons, a new analysis is warranted to see whether state geographic entry restrictions on retail vehicle dealerships increase car prices and reduce consumer welfare. 


\section{A MODEL FOR ANALYZING VARIATION IN VEHICLE PRICES}

Consider the following simple demand and supply equation system for new vehicles.

$$
\begin{aligned}
& \text { (1) } Q_{d}=a-b P+e S D \text {, and } \\
& \text { (2) } Q_{s}=-c+d P+f S S \text {, }
\end{aligned}
$$

where $Q_{d}$ is vehicle demand, $Q_{s}$ is vehicle supply, $P$ is the equilibrium vehicle price, $S D$ is a vector of demand curve shifters, and $S S$ is a vector of supply curve shifters. Following Chiang (1974, p. 21), $a, b, c$, and $d$ are positive parameter values. ${ }^{3}$ Setting $Q_{d}$ equal to $Q_{s}$ and solving for $P$ gives:

$$
P=\frac{a}{b+d}+\frac{c}{b+d}+\frac{e}{b+d} S D-\frac{f}{b+d} S S
$$

Equation (3) is the reduced form equation. The denominator $(b+d)$ is positive, as are the first two terms since $a$ and $c$ are positive. The parameter $e$ is the coefficient on the demand shifter in equation (1). It is positive for factors that increase demand and so increase price, and it is negative for factors that decrease demand and thus decrease price. Parameter $f$ is the coefficient on the supply shifter in equation (2). It is positive in equation (2) for factors that increase supply, but since it is preceded by a negative sign in equation (3), factors that increase supply result in a lower price. Conversely, parameter $f$ is negative in equation (2) for factors that decrease supply and, consequently, thus increase price in equation (3).

The empirical reduced form equation used in the analysis is a collection of factors that shift the demand curve or the supply curve. Factors that increase demand or reduce supply should be associated with a higher price, while factors that decrease demand or increase supply should be related to a lower price.

The empirical reduced form equation is:

$$
\begin{aligned}
& \text { PRICE = } f \text { (INCOME, GASPRICE, INSPRICE, SALESTAX, POP1535, POP55, } \\
& \text { HHSIZE, INTERNET, DEALERIV, DISTANCE, DENSITY, SIP, RMAHAVE, } \\
& \text { RMAHAVE*POPGRWTH, NORTHEAST, MIDWEST, WEST, BLKCOLOR, } \\
& \text { SILCOLOR, OTHCOLOR, AUTOTRAN, SIDEBAGS, ADDMIRRS, } \\
& \text { DXNOAC, DXAC). }
\end{aligned}
$$

\footnotetext{
${ }^{3}$ The negative sign preceding parameter $c$ is set to insure that a sufficiently high price is required to bring forth any supply.
} 
Table 1 defines the variables and their sources. The dependent variable, PRICE, is the dealer price quote, or offer price, including destination charges and dealer preparation for a 2003 Honda Accord LX model with a beige exterior and ivory cloth interior. The standard features for this model are listed in Table 2 . The vehicle is modestly equipped with a four cylinder engine and manual transmission. A Honda Accord was selected because it is the most popular selling vehicle in the domestic U.S. market (Business Week 2002). Using the Honda Web site (hondacars.com), a price quote was requested for the 2003 Honda Accord LX from each of the 1,124 Honda dealerships in the U.S. ${ }^{4}$ Between May 13, 2003 and June 17, 2003, price quotes for the specified vehicle were received from 539 dealers, for a response rate of 48 percent.

There are two advantages of this measure of PRICE compared to previous studies. First, specific features of the vehicle are held constant, meaning any price variability should not be related to variation in features and amenities. The inability to account for differences in features was a major problem of the three previous studies, as already noted. Second, since the prices were collected within a 36 day period, any price changes resulting from changes in manufacturer's financial incentives or dealership costs should be minimal. Price changes of substitutes and complements should also be limited. Previous studies used prices or price estimates spanning an entire year, enough time for changes in cost factors or manufacturer's incentives to affect the price. A disadvantage of the PRICE measure is its limitation to one vehicle model. However, there is no reason to expect the economics of retail vehicle pricing to be significantly different for Honda than for other brands.

Following Rogers (1986), the geographic area used for market-wide characteristics is the county. Also replicating Rogers, INCOME, GASPRICE, INSPRICE, SALESTAX, POP1535, POP55, and HHSIZE are included as demand shifters. Ceteris paribus, increases in per capita income (INCOME) will increase (decrease) the demand curve and increase (decrease) PRICE if the Honda Accord is a normal (inferior) good.

The effect of GASPRICE will depend on the net result of two countering effects. Since gasoline and vehicles are complementary goods, the effect of a higher GASPRICE will be to shift the demand curve downward and reduce PRICE. However, since Honda vehicles are recognized to have high fuel efficiencies, an increase in GASPRICE may cause a substitution away from other vehicle brands to Honda, an increase in the demand curve, and an increase in PRICE. The direction of the effect of GASPRICE on PRICE will depend on the relative strength of these competing actions.

\footnotetext{
${ }^{4}$ All Honda dealerships have Web sites. J.D. Power estimates 40 percent of new vehicle shoppers used the Internet in 1999, with the percentage likely rising to 65 percent in a year (Pastore 1999). Although the initial Internet price quote may not be the final transaction price, the relative differences between the quotes are the important aspect for this study. Also, an advantage of the initial price quote is it eliminates any impacts of buyer negotiation skills on the final transaction price.
} 
TABLE 1

Variables and Data Sources Used in Vehicle Price Equation

\begin{tabular}{|c|c|}
\hline VARIABLE & DEFINITION AND SOURCE \\
\hline \multirow{2}{*}{$\begin{array}{l}\text { PRICE } \\
\text { INCOME }\end{array}$} & Dealer price quote for a 2003 Honda Accord, LX model, 4 door sedan ${ }^{\mathrm{a}}$ \\
\hline & Per capita income of county in which dealer is located ${ }^{\mathrm{b}}$ \\
\hline & $\begin{array}{l}\text { Price per gallon of unleaded gasoline in June, } 2003 \text { in state in which dealer is } \\
\text { located }^{\text {c }}\end{array}$ \\
\hline INSPRICE & $\begin{array}{l}\text { Average annual auto insurance premium in } 2000 \text { for liability, collision, and } \\
\text { comprehensive coverage in state in which dealer is located }^{\mathrm{d}}\end{array}$ \\
\hline SALESTAX & State sales tax on vehicle purchase ${ }^{e}$ \\
\hline POP1535 & $\begin{array}{l}\text { Percentage of population between } 15 \text { and } 35 \text { years old in county in which dealer } \\
\text { is located }\end{array}$ \\
\hline POP55 & Percentage of population 55 years and older in county in which dealer is located \\
\hline HHSIZE & Average household size in county in which dealer is located ${ }^{\mathrm{b}}$ \\
\hline INTERNET & $\begin{array}{l}\text { Percentage of households with internet access in 2001in state in which dealer is } \\
\text { located }^{\text {b }}\end{array}$ \\
\hline DEALERIV & Dealer invoice cost ${ }^{f}$ \\
\hline DISTANCE & $\begin{array}{l}\text { Driving distance, in miles, of dealership from Honda assembly plant in } \\
\text { Marysville, Ohio }{ }^{\mathrm{g}}\end{array}$ \\
\hline DENSITY & Population density in county in which dealer is located ${ }^{\mathrm{b}}$ \\
\hline SIP & 1 if dealer offered special price for internet shoppers; 0 otherwise ${ }^{a}$ \\
\hline RMAHAVE & 1 if state has an RMA; 0 if state has no RMA ${ }^{\mathrm{h}}$ \\
\hline RMAHAVE* & Interaction term between RMAHAVE and population growth (POPGRWTH) \\
\hline POPGRWTH & from year of RMA adoption to 2000 in county in which dealer is located ${ }^{\mathrm{b}, \mathrm{h}}$ \\
\hline NORTHEAST & $\begin{array}{l}1 \text { if dealer is in the states of Connecticut, Maine, Massachusetts, New } \\
\text { Hampshire, Rhode Island, Vermont, New Jersey, New York, or Pennsylvania; } 0 \\
\text { otherwise }^{\text {b }}\end{array}$ \\
\hline MIDWEST & $\begin{array}{l}1 \text { if dealer is in the states of Indiana, Illinois, Michigan, Ohio, Wisconsin, Iowa, } \\
\text { Kansas, Minnesota, Missouri, Nebraska, North Dakota, or South Dakota; } 0 \\
\text { otherwise }^{b}\end{array}$ \\
\hline WEST & $\begin{array}{l}1 \text { if dealer is in the states of Arizona, Colorado, Idaho, New Mexico, Montana, } \\
\text { Utah, Nevada, Wyoming, Alaska, California, Hawaii, Oregon, or Washington; } 0 \\
\text { otherwise }^{b}\end{array}$ \\
\hline BLKCOLOR & 1 if vehicle color is black; 0 otherwise ${ }^{\mathrm{a}}$ \\
\hline SILCOLOR & 1 if vehicle color is silver; 0 otherwise ${ }^{\mathrm{a}}$ \\
\hline OTHCOLOR & 1 if vehicle color is other then beige, black, or silver; 0 otherwise ${ }^{a}$ \\
\hline AUTOTRAN & 1 if vehicle has automatic transmission; 0 otherwise ${ }^{a}$ \\
\hline SIDEBAGS & 1 if vehicle has side airbags; 0 otherwise ${ }^{\mathrm{a}}$ \\
\hline ADDMIRRS & 1 if vehicle has additional mirrors; 0 otherwise ${ }^{\mathrm{a}}$ \\
\hline \multirow{2}{*}{$\begin{array}{l}\text { DXNOAC } \\
\text { DXAC }\end{array}$} & 1 if vehicle model is DX with no air-conditioning; 0 otherwise ${ }^{a}$ \\
\hline & 1 if vehicle model is DX with air-conditioning; 0 otherwise ${ }^{\mathrm{a}}$ \\
\hline \multicolumn{2}{|l|}{ Sources: } \\
\hline
\end{tabular}


TABLE 2

Features of the 2003 Honda LX Model Used in the Analysis

\section{Technical Features}

160 hp, 2.4 liter, 16 value DOHC i-VTECA 4-cylinder engine, 5-speed manual transmission, front stabilizer bar, double wishbone front suspension, five-link double wishbone rear suspension, variable-assist power rack and pinion steering, front disc rear drum brakes, 110,000 mile scheduled tune-up interval

Safety Features

anti lock braking system, dual stage front airbags, front and rear 3 point seat belts, full frontal offset frontal and side impact protection, lower anchors and tethers for children Interior Features

power windows with auto down driver's window, center console armrest with storage compartment, AM/FM/CD audio system with 2 speakers, Tilt and telescopic steering column Exterior Features

integrated real window antenna, wheels with full covers, multi reflector halogen headlights, impact absorbing body colored bumpers, breakaway mirrors

Source: Hondacars.com

INSPRICE is the price of a complementary good to vehicles, and as such increases in INSPRICE will, ceteris paribus, reduce the demand curve for vehicles and reduce PRICE. SALESTAX is the excise tax paid by buyers on vehicle purchase. Although a buyer excise tax will reduce the demand curve, except in the case of a perfectly inelastic supply curve, PRICE (including the tax) will be higher than without the tax. POP1535, POP55, and HHSIZE are important household age and household size variables that can affect the preferences of households for specific vehicles and can therefore shift the demand curve.

INTERNET is expected to affect PRICE by changing the elasticity of the demand curve. Residents of states with greater Internet use could be expected to shop more dealers and therefore have a more elastic demand curve than residents of states with less Internet use. Consequently, dealers may segment the market based on Internet use, with states having higher values on INTERNET representing buyers with a more elastic demand curve who are offered a lower PRICE, while states with lower values on INTERNET signifying buyers with a more inelastic demand curve who are offered a higher PRICE.

DEALERIV and DISTANCE are supply shifters. The Eckard (1985)and Rogers (1986) studies included the wholesale vehicle price as a determinant of the retail price. These wholesale prices were proprietary company data, and such data were not available for the current study. However, the Website buyingadvice.com provides invoice costs for specific vehicle models sold at the buyer's zip code. We used the zip codes of the Honda dealers to obtain the dealer invoice (DEALERIV) for each dealer. Because there may be error in this measure of the dealer invoice, the distance of the dealer to the single U.S. 
Honda assembly plant in Marysville, Ohio was also included as a supply shifter. Increases in DEALERIV and DISTANCE are both expected to shift upward the supply curve and increase PRICE.

Population density (DENSITY) can be both a supply curve and demand curve shifter. As a supply shifter, greater population may be related to higher real estate costs, thereby causing an upward shift in the supply curve and a higher PRICE. Alternatively, higher population density can be associated with greater economies of scale for some inputs and a consequent downward shift in the supply curve and a lower PRICE. As a demand shifter, Rogers (1986) argues greater population density is related to a greater availability of private vehicle alternatives like taxis, buses, and other mass transit. The increased prevalence of such alternatives would cause a downward shift in the demand curve and a lower PRICE. The relative strength of these individual effects will determine the sign on DENSITY.

Some dealers may price discriminate between buyers using the Internet for shopping and those not, expecting the demand curve for Internet shoppers to be more price elastic and therefore offering them a lower PRICE. To test this possibility, a categorical variable, SIP, is included. SIP is set at 1 for dealers who indicated a special price for Internet shoppers and set at 0 for other dealers.

Two variables are used to model the restrictions imposed by retail market areas. The first is the categorical variable, RMAHAVE, measured as 1 if the state has a statute permitting existing dealers to challenge a proposed new dealership and 0 if it doesn't. As in Rogers (1986), the second variable is an interaction between RMAHAVE and the market area's (county) population growth from the time the statute was adopted to 2000 (RMAHAVE*POPGRWTH). This interaction term tests whether retail market area restrictions impact PRICE more in faster growing markets. A positive coefficient on RMA*POPGRWTH would support this hypothesis.

To account for unmeasured consumer taste and preference variables, three regional variables are included, NORTHEAST, MIDWEST, and WEST. The categories use the Census Bureau's combinations of states into regions. The south region is the omitted category.

Although dealer offer prices were requested for the same Honda Accord with the same characteristics, some dealers did not provide a price quote for the exact prototype. Therefore, several categorical variables were added to the equation to represent features different than the prototype. BKKCOLOR, SILCOLOR, and OTHCOLOR control for an external color other than beige. A price quote for a Honda LX model with automatic transmission is represented by AUTOTRAN, with side airbags included is measured by SIDEBAGS, and with additional mirrors is indicated by ADDMIRRS. Some dealers provided a price quote for a DX model with no air conditioning (DXNOAC), and others sent a price quote for a DX model with air conditioning (DXAC). Coefficients on these variables represent price differences for the features apart from discounts or premiums 
reflected in the dealer invoice cost. For example, a negative coefficient on AUTOTRAN doesn't mean vehicles with automatic transmission cost less than those with manual transmission. Rather it means that, after controlling for the impact of an automatic transmission on the dealer invoice cost, a discount occurs at the retail price compared to vehicles with manual transmission.

\section{RESULTS AND ANALYSIS}

Table 3 presents descriptive statistics for the variables used in the analysis. Examination of the correlation matrix for the independent variables reveals most bivariate correlations under 0.30 and only one above 0.40 , a correlation coefficient of 0.79 between DISTANCE and GASPRICE. Therefore, with this exception, collinearity should not be an issue in the analysis. ${ }^{5}$

Two econometric issues with the data and model were addressed. First is the issue of potential sample selection bias. Since not all dealers responded to the price request, the possibility existed that the characteristics of the respondents were significantly different than those of the non-respondents. To investigate this issue, the Heckman two-stage procedure for sample selection bias was applied. In the first stage, a probit procedure was used to regress a categorical variable indicating a dealer response or non-response on all the right-hand side variables from equation (4). In the second stage, the inverse Mills ratio (lambda) from stage one was used with the other explanatory variables in estimating PRICE. Since the parameter estimate on lambda was not statistically significant, sample selection bias was judged not to be a problem.

The second issue was the possible endogeniety of RMAHAVE. Rather than being exogenous, the presence or absence of vehicle dealer entry restrictions could be a result of political and auto market factors in the state. If present, this condition introduces simultaneous equation bias. To test for this bias, a two equation model was used, one equation being equation (4) and the other being an equation regressing RMAHAVE on the other exogenous variables plus six variables describing the political and auto market environment in the state. The additional six, all used by Rogers (1986), were the percentage of state employment in auto manufacturing, the percentage of state employment in auto dealerships, the number of state legislative seats, the ratio of lower house legislative seats to upper house legislative seats, state per capita income, and state population. A Hausman test indicated RMAHAVE could be treated as exogenous. Hence, a single equation OLS model is used in the analysis.

The regression results are presented in Table 4. The model explains 80 percent of the variation in PRICE. Since the parameter estimates on GASPRICE and DISTANCE are both statistically significant, the high correlation between these two variables apparently does not affect the empirical results.

\footnotetext{
${ }^{5}$ Systematic regressions of each independent variable on all other independent variables were also performed, and no further evidence of collinearity issues was found.
} 
TABLE 3

Descriptive Statistics

\begin{tabular}{lcc}
\hline Variable & Mean & Standard Deviation \\
\hline PRICE (\$) & 17,724 & 1,100 \\
INCOME (\$) & 22,657 & 4,948 \\
GASPRICE (\$) & 1.53 & 0.16 \\
INSPRICE & 688 & 116 \\
SALESTAX (\%) & 5.08 & 1.42 \\
POP1535 (\%) & 28.4 & 4.2 \\
POP55 (\%) & 20.6 & 4.5 \\
HHSIZE (persons) & 2.59 & 0.21 \\
INTERNET (\%) & 50.5 & 5.8 \\
DEALERIV (\$) & 16,938 & 988 \\
DISTANCE (miles) & 1,042 & 850 \\
DENSITY (persons) & 1,278 & 2,967 \\
SIP & 0.53 & 0.50 \\
RMAHAVE & 0.91 & 0.29 \\
RMAHAVE * POPGRWTH & 242,312 & 523,296 \\
NORTHEAST & 0.19 & 0.39 \\
MIDWEST & 0.20 & 0.40 \\
WEST & 0.25 & 0.43 \\
BLKCOLOR & 0.002 & 0.043 \\
SILCOLOR & 0.050 & 0.218 \\
OTHCOLOR & 0.011 & 0.011 \\
AUTOTRAN & 0.056 & 0.229 \\
SIDEBAGS & 0.017 & 0.128 \\
ADDMIRRS & 0.069 & 0.253 \\
DXNOAC & 0.102 & 0.303 \\
DXAC & 0.026 & 0.159 \\
N & 539 & - \\
\hline & & \\
& &
\end{tabular}

The negative and statistically significant parameter estimate on INCOME suggests the Honda Accord is an inferior good. While at first glance this finding may seem peculiar, when it is recalled that the Accord model used in the analysis is modestly equipped and modestly priced, it seems reasonable that increases in income motivate the buyer to move up to better equipped models or brands.

GASPRICE has a negative and statistically significant sign, suggesting the general complementary relationship between vehicles and gasoline dominates the fuel efficiency effects of the Honda Accord. Whereas no statistically significant relationship was found 
between insurance premiums (INSPRICE) and PRICE, SALESTAX does have the expected positive sign. None of the demographic variables (POP1535, POP55, and HHSIZE) have statistically significant parameter estimates, but a greater availability of Internet service (INTERNET) in the state is associated with lower values of PRICE.

TABLE 4

Regression Results (Dependent Variable: PRICE)

\begin{tabular}{|c|c|c|}
\hline Explanatory Variable & Coefficient & T-Statistic \\
\hline Intercept & -1130.07 & -0.57 \\
\hline INCOME (thousands) & -15.36 & $-2.86^{\mathrm{a}}$ \\
\hline GASPRICE & -920.99 & $-2.53^{\mathrm{b}}$ \\
\hline INSPRICE & -0.03 & -0.09 \\
\hline SALESTAX & 35.36 & $1.98^{\mathrm{b}}$ \\
\hline POP1535 & 7.31 & 0.80 \\
\hline POP55 & 14.09 & 1.39 \\
\hline HHSIZE & 80.90 & 0.48 \\
\hline INTERNET & -8.77 & $-1.82^{\mathrm{c}}$ \\
\hline DEALERIV & 1.19 & $11.49^{\mathrm{a}}$ \\
\hline DISTANCE & 0.24 & $3.80^{\mathrm{a}}$ \\
\hline DENSITY & -0.01 & -1.51 \\
\hline SIP & -429.42 & $-9.11^{\mathrm{a}}$ \\
\hline RMAHAVE & -164.96 & $-1.80^{c}$ \\
\hline RMAHAVE*POPGRWTH (thousands) & -0.24 & $-4.24^{\mathrm{a}}$ \\
\hline NORTHEAST & 93.53 & 0.99 \\
\hline MIDWEST & 159.73 & $2.12^{\mathrm{b}}$ \\
\hline WEST & 175.91 & 1.40 \\
\hline BLKCOLOR & 153.14 & 0.30 \\
\hline SILCOLOR & 38.26 & 0.38 \\
\hline OTHCOLOR & 42.70 & 0.20 \\
\hline AUTOTRAN & -222.64 & $-1.71^{\mathrm{c}}$ \\
\hline SIDEBAGS & 368.83 & $2.11^{\mathrm{b}}$ \\
\hline ADDMIRRS & 224.77 & $2.50^{\mathrm{b}}$ \\
\hline DXNOAC & 665.70 & $2.07^{\mathrm{b}}$ \\
\hline DXAC & 329.70 & 1.34 \\
\hline $\mathrm{R}^{2}$ & $0.80^{\mathrm{a}}$ & - \\
\hline $\mathrm{N}$ & 539 & - \\
\hline 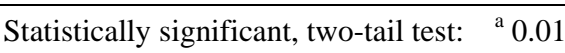 & vel; ${ }^{\mathrm{b}} 0.05$ level & ; ${ }^{\mathrm{c}} 0.10$ leve \\
\hline
\end{tabular}


DEALERIV and DISTANCE have the expected positive and statistically significant parameter estimates. The results for DEALERIV imply dealers mark-up invoice costs by an average of 19 percent. Also, PRICE rises by an average of 24 cents for every additional mile from the Honda assembly plant. The parameter estimate on DENSITY is negative but not statistically significant, likely reflecting the summary of the variable's multiple effects. Buyers using the Internet for shopping (SIP) receive an average price discount of $\$ 429$. Among the regional variables, buyers in the Midwest pay about $\$ 160$ more for the Honda Accord than buyers in the South. After controlling for their impacts on the dealer invoice, buyers pay a retail price premium for side air bags (SIDEBAGS), additional mirrors (ADDMIRRS), and a DX model with no air conditioning (DXNOAC) and receive a retail price discount for automatic transmission (AUTOTRAN).

The focus of the study, the price impact of state dealer entry restrictions, is measured by the results for the variable RMAHAVE and the interaction variable RMAHAVE * POPGRWTH. The parameter estimates for both terms are negative and statistically significant. Thus, this study gives no support for the hypothesis that state dealer entry restrictions increase retail vehicle prices.

Two other versions of the model were run. One version replaced RMAHAVE with the radius mileage of the retail market area. In this case, states without dealer entry restrictions were recorded as having a radius mileage of zero. The results showed no positive effect of the entry restrictions on vehicle price. A second version replaced RMAHAVE with the radius mileage of the retail market area but omitted observations from states where the manufacturer, not the state, set the radius mileage. The issue this created was that Honda declined to provide information on its manufacturer-set radius mileage. Nevertheless, in this alternative model the substantive results were the same.

\section{IMPLICATIONS AND CONCLUSIONS}

Previous studies have found that state restrictions on the entry of vehicle dealerships into the market have resulted in higher vehicle prices and lost welfare for consumers. However, the studies suffer from data measurement problems, are now dated, and were conducted prior to the development of Internet shopping.

Using price data collected on-line from Honda dealers across the country for a new vehicle exactly the same in all characteristics, an analysis found no positive price effect from dealership entry restrictions. Instead, the determinants of the cross-sectional variation in the retail price included the dealer's invoice price, distance from the Honda assembly plant, other prices such as the local gasoline price and state excise tax rate, Internet availability and use, and income. The two entry restriction variables actually had negative effects on PRICE. Interestingly, since the Honda vehicle used in the analysis was a basic model with modest features, the model was found to be an inferior good.

The important question is why did the impact of dealership entry restrictions change over the 25 years since the last studies were conducted. There are three possible reasons. 
One is the improved quality of the data used in the current study compared to earlier analyses. As emphasized, previous studies were possibly flawed due to their inability to control for differences in vehicle features that could clearly affect the vehicle price. The current study overcame this issue by carefully comparing the prices of only the exact same vehicle. Therefore, it's unknown whether the earlier studies accurately measured the price impact of the entry restrictions or whether the restriction's impacts have, indeed, changed over time.

A second explanation involves the success of proposed dealerships in arguing for their entry into the market. In states with entry restrictions, it may be that groups proposing new dealerships have become better, over time, at convincing the state boards to grant their request. Perhaps state boards have come to realize the value of enhanced competition. Unfortunately, no available studies have tested this hypothesis, so it must remain a supposition.

Last, the central finding of the study may simply represent a triumph of technology over artificial barriers. The development of Internet shopping, the growth in mass media advertising, and the increased willingness of buyers to consider shopping in many market areas may have rendered the restrictions irrelevant. So although entry restrictions remain as state statutes, their effectiveness is negated by sellers and buyers interacting in wider geographic areas than those represented by the RMAs. The significance of the two Internet measures lends support to this theory.

This still leaves unanswered why the entry restriction variables were found to have a negative effect on PRICE. One possibility is the five states without such regulations share a characteristic or characteristics that have not been captured in the model and that act to lower vehicle prices in general or Honda Accord prices in particular, compared to the other states. ${ }^{6}$ Another explanation is that entry restrictions motivate enough additional competition between dealers in adjacent retail market areas that prices are actually lowered.

This study should by no means be the last on dealer entry restrictions in the vehicle market. Research can be extended on many topics. First is the obvious need to replicate the study by using other vehicle models or multiple models. Key in this endeavor is the requirement of collecting prices for the exact same vehicle over a very short time period.

Second, an examination of the actions of the state boards enforcing the entry restrictions could provide insightful information. What percent of the entry requests have been denied by these boards, and how has this rate changed over time? What role, if any, have the state boards played in changing the impact of the entry restrictions?

\footnotetext{
${ }^{6}$ A reviewer offered this suggestion. The five states without entry restrictions, with the number of sample dealers in parentheses, are Maryland (14), Mississippi (4), Montana (2), New York (27), and North Dakota (3).
} 
A useful third extension would be an analysis of changes over time in the shopping behavior of vehicle buyers and how these changes have influenced the effectiveness of the entry restrictions. It would seem that information technology, modern mass advertising, and the greater mobility of households would have expanded the market area used by both buyers and sellers.

Fourth would be further investigation into the possibility that entry restrictions could lead to lower, not higher, prices. If entry restrictions result in fewer, and more dominant, dealers within each market, what are the conditions under which these strong dealers are more effective inter-market area competitors, and when might this competition cause lower prices?

Globalization has created borderless market areas in most of the world. In such an environment, artificial barriers erected by governments are increasingly being bypassed and made meaningless. One such domestic example may be the vehicle dealer entry restrictions found in many states. While in an earlier time they may have effectively limited competition and raised prices, in today's tech-directed world with savvy shoppers, they may be as out-of-date as buggy regulations!

\section{REFERENCES}

Business Week, 2002. “An Edgy Family Car,” December 2, available at www. businessweek.com.

Chiang, A.C., 1974. Fundamental Methods of Mathematical Economics, 2nd Edition. McGraw-Hill: New York.

Daniel, T. and A. Kleit, 1995. Disentangling Regulatory Policy: The Effects of State Regulations on Trucking Rates, Federal Trade Commission: Washington, D.C.

Eckard. E.W, Jr., 1985. "The Effects of State Automobile Dealer Entry Regulation on New Car Prices,” Economic Inquiry 24(2), 223-242.

Federal Trade Commission, 1987. Letters to New York City and Chicago City Councils On Taxicab Regulation. U.S. Government Printing Office: Washington, D.C. , 2004. Improving Health Care: A Dose of Competition. U.S. Government Printing Office: Washington, D.C.

Florida Office of Program Analysis and Government Accountability, 1996. Review of the Automobile Manufacturer Licensing Program, No. 95-41. Tallahassee, FL.

Liang, J.N and J. Ogur, 1987. Restrictions on Dental Auxiliaries. Federal Trade Commission: Washington, D.C.

Pastore, M., 1999. “40 Percent of Vehicle Shoppers Use Internet,” Clickz Network, August 26, available at www.clickz.com.

Rogers, R.P. ,1986. The Effect of State Entry Regulation on Retail Automobile Markets, Bureau of Economics Staff Report. Federal Trade Commission: Washington, D.C.

Smith, R.L.,1982. "Franchise Regulation: An Economic Analysis of State Restrictions on Automobile Distribution," Journal of Law and Economics 25(1), 125-157.

U.S. Bureau of Labor Statistics, 2003. Consumer Expenditure Survey, 2001, available at www.bls.gov. 